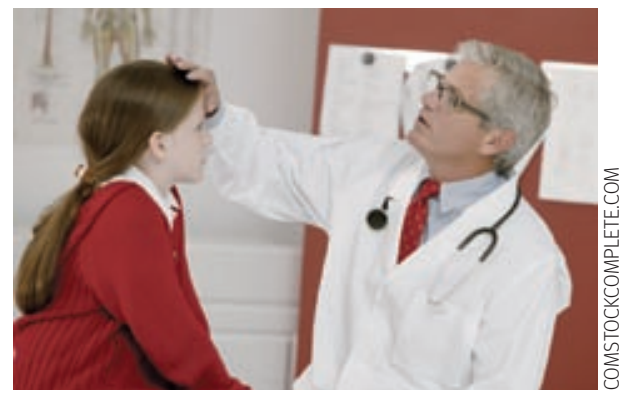

\section{SPOTTING THE SICK CHILD}

\section{Video clip is worth 1000 words}

Identifying a seriously ill feverish child, as opposed to one who is miserable and irritable because he or she is uncomfortable with a simple condition, requires care and experience. Harnden reminds us that there is no simplistic formula; a full assessment is needed in which a careful examination is more important than the history, which is why "telephone triage" can be dangerous. A further review is important as the condition of children evolve and change rapidly. ${ }^{1} \mathrm{He}$ also points out that the guidelines from the National Institute for Health and Clinical Excellence (NICE) for children with fever and its traffic light system is of limited value. ${ }^{2}$ These matters are of importance because fewer general practitioners see patients "out of hours," so increasing numbers of first consultations in the United Kingdom are now delegated to telephone screening and staff in walk-in centres with limited experience. Also it is difficult for staff to gain experience and see many seriously ill children during training because of shorter hours and relatively fewer critically ill children.

To give health workers the experience to identify seriously ill children, modern technology, in the form of video clips, CDs, and DVDs, must play a larger part in training. "Spotting the sick child" is a very good DVD produced for the Department of Health by Ffion Davies and colleagues in the accident and emergency departments of Leicester Royal Infirmary and the Royal London Hospital. ${ }^{3} \mathrm{~A}$ practical introduction and demonstration of a simple but rapid examination routine is followed by clips of many children with difficult breathing, fever, dehydration, abdominal pain, etc. Some even show the progression of the condition. The second is a CD produced for the World Health Organization by Trevor Duke and others of Melbourne University, Australia. It supports and illustrates a recent WHO publication on hospital care for children. ${ }^{45}$ It contains three video clips of ill children and many still images, all in a context to reinforce the method set out in the book. There must be other good teaching videos, CDs and DVDs out there, but there is scope and need to produce and share such practical teaching material.

William A M Cutting, retired paediatrician University of Edinburgh, Edinburgh EH91UW william.cutting@talktalk.net WAMC is adviser to TALC (Teaching Aids at Low Cost). Competing interests: None declared.

1 Harnden A. Recognising serious illness in feverish young children in primary care. BMJ 2007;335:40910. (1 September.)

2 National Institute for Health and Clinical Excellence. Feverish illness in children - assessment and initial management in children younger than 5 years. 2007 (NICE Clinical guideline No 45.)http://guidance, nice. org.uk/CG47.

3 Davies F. The 3-minute toolkit. Spotting the sick child. DVD, 2004. www.ocbmedia.com/product-42 SpottingtheSickChild.html

4 World Health Organization, Child and Adolescent Health and Development. Pocket book of hospital care for children. Guidelines for the management of common illnesses with limited resources. WHO: Geneva, 2005.

5 Duke T, Manandhar N, Hennessey M, Kelly J, Paterson $R$, Auge A, et al. Hospital care for children. A CD ROM training resource for the management of common illnesses with limited resources. 2006. (To be used in conjunction with the WHO Pocket book of hospital care for children.)

\section{Face to face always}

Performing snapshot assessments in emergency settings is notoriously risky. Serial assessment of the child is not always possible. A scientific approach of measuring heart rate, capillary refill, respiratory rate, and behaviour takes less than 3 minutes $^{1}$ and is achievable in these settings. Harnden is wrong in saying that this is not achievable in primary care. ${ }^{2}$ To state that there is no evidence that measurement of these parameters helps identify serious bacterial illness may be true for primary care but is not true in hospital (emergency department or paediatric wards). Logic dictates that a similar assessment should take place in primary care.

The Intercollegiate Advisory Group for Services for Children in Emergency Departments has concerns about the abilities of telephone triage systems and inadequately trained frontline staff to differentiate seriously ill children from children with self limiting febrile illness In the wake of the new General Medical Services contract, increasing numbers of parents access telephone advice, emergency departments or primary care centres for assessment of their febrile infant (particularly out of hours). These points of contact must ensure staff have basic paediatric assessment skills. ${ }^{3}$ To substitute experienced primary care, emergency medicine and paediatric staff with cheaper alternatives is not necessarily a safe strategy. The low incidence of serious bacterial illness means that most of the time, most children will come to no harm. This is no consolation for the parent of a seriously ill child.

Ffion C Davies, consultant in emergency medicine Leicester Royal Infirmary, Leicester LE15WW Ffion.davies@uhl-tr.nhs.uk FCD is chair, Intercollegiate Advisory Group for Services for Children in Emergency Departments.

Competing interests: None declared.

1 Davies F. The 3-minute toolkit. Spotting the sick child. DVD, 2004. www.ocbmedia.com/product-42SpottingtheSickChild.html

2 Harnden A. Recognising serious illness in feverish young children in primary care. BMJ 2007;335:409-10. (1 September.)

3 Royal College of Paediatrics and Child Health. Services for children in emergency departments (intercollegiate report) 2007. www.rcpch.ac.uk/Health-Services/ Emergency-Care

\section{NICE BEHAVIOUR}

\section{QALYs in the community}

One of the major concerns of rheumatologists (who have been involved with submissions to the National Institute for Health and Clinical Excellence (NICE) for a series of expensive drugs for the treatment of rheumatoid arthritis and other inflammatory joint diseases) is "what is contained in a QALY assessment." The answer, many believe, is not enough. If it were clear that there was a cost assessment of the potential reduction in orthopaedic costs, of the economic cost of putting 
someone on the sick register, or of the similar costs to carers, then we might be happier to accept that patients might be denied treatment.

If someone with rheumatoid arthritis is turned from a working taxpayer into a benefit recipient then the drug cost might be totally offset by the difference between the tax revenue lost added to the disability benefits paid. For biological agents, which are often considered in people of working age, the income level of a patient to be in positive credit balance may be quite low.

There is the additional question of whether the use of biological agents and other similar drugs might, if given early enough, provoke sustained disease remissions-which would reduce the medical on-costs of the drugs themselves. Much as I hate to use that hackneyed phrase "more research is needed," it would be helpful to have clear answers to these two questions.

Andrew N Bamji, consultant rheumatologist Queen Mary's Hospital, Sidcup, Kent DA146LT bamji@btinternet.com Competing interests: ANB is a physician with an interest in offering effective and expensive treatments to patients, and current president of the British Society for Rheumatology.

1 Appleby J, Devlin N, Parkin D. NICE's cost effectiveness threshold. BMJ 2007;335:358-9. (25 August.)

\section{ME guideline is unworkable}

NICE recommends that everyone with mild or moderate myalgic encephalopathy/chronic fatigue syndrome (ME/CFS) should be offered a course of either cognitive behaviour therapy (CBT) or graded exercise therapy (GET). ${ }^{1}$

This is despite published evidence remaining weak (especially for group CBT) and inconsistent ${ }^{2}$. Patient evidence submitted to the chief medical officer's report concluded that CBT produced "no change" in 67\% of cases and made the condition "worse" in 26\% of cases. Around 50\% of respondents reported that inappropriate exercise therapy had also made their condition "worse." 3

When the NICE estimate on prevalence is used this recommendation will affect some 200000 people. A one to one course of CBT covering 12 to 16 sessions will cost well over $£ 1500$. The cost of a professionally supervised exercise therapy programme is also likely to be substantial.

So where is around $£ 300$ million of new money going to come from at a time when very limited funding for some of the newly established NHS clinical services for people with $\mathrm{ME} / \mathrm{CFS}$ is now being cut? ${ }^{4}$ And where are all the therapists going to come from? Those already in post often cannot even cope with their current workload.

These are important questions that I raised at a NICE implementation and planning meeting in October 2006-but nobody from NICE could provide a convincing answer. These recommendations are going to be of no value whatsoever to many people with $\mathrm{ME} / \mathrm{CFS}$. They are also going to be impossible to implement owing to a lack of both funding and human resources.

Charles B Shepherd, medical adviser ME Association, Buckingham MK181TH charles.c.shepherd@btinternet.com Competing interests: Physician with personal experience of this illness.

1 Baker R, Shaw EJ. Diagnosis and management of chronic fatigue syndrome or myalgic encephalomyelitis (or encephalopathy): summary of NICE guidance. BMJ 2007;335:446-8. (1 September.)

2 Shepherd C, Chaudhuri A. ME/CFS/PVFS-an exploration of the key clinical issues. Buckingham: ME Association, 2007.

3 CFS/ME Working Group. A report of the CFS/ME working group: report to the chief medical officer of an independent working group. London: Department of Health, 2002

4 MEAssociation. Summary of key points to emerge from All Party Parliamentary Group meeting held in Committee Room 17 at the House of Commons on Thursday 12 July. www.meassociation.org.uk/ content/view/307

\section{TIME TO DROP EPONYMS?}

\section{Curbing Medicalese is the issue}

Blanket abandonment of eponyms cannot be argued successfully. ${ }^{1}{ }^{2}$ Surely the real question is whether Medicalese (including excessive use of eponyms) should be abandoned; or at least brought to heel. The scholarly dandification of the English language by post-renaissance travellers around the 16 th and 17 th centuries $\mathrm{AD}$ included the absorption and reworking of classical terms from Greek and Latin. This represented an inversion of the hard won earlier rejection of Latin as the exclusive language of knowledge and powers. As such, this new tendency (with flourishing sciences such as medicine among the prime movers) was much criticised by linguists of the day. However, it continued apace until English had once again become a useful way of distinguishing educated from ignorant, and rich from poor.

Language is a tool for communication. Corrupting its function for reasons of smug scholarly vanity, professional protectionism, or simple laziness can hardly be of service to our patients, since it diminishes our capacity to communicate with them and each other. If we believe in patient centred care, health empowerment, or even just the resurgence of the vernacular, then we must stop hiding behind our clever eponyms and pseudoclassical tosh, and start saying what we mean

David J Ogden, consultant psychiatrist Fan Gorau Unit, Montgomery County Infirmary, Powys Local Health Board, Newtown, Powys SY16 2LT davidogden@yahoo.com Competing interests: None declared.

1 Woywodt A, Matteson E. Should eponyms be abandoned? Yes. BMJ 2007;335:424. (1 September.)

2 Whitworth JA. Should eponyms be abandoned? No. BMJ 2007;335:425. (1 September.)

\section{JOB FOR LIFE}

\section{Satan what done it}

Launer does a great service in describing the Book of Job as the most enduring handbook for any of us who have to deal professionally with tragedy, loss, or despair. ${ }^{1}$ The opening paragraph, however, contains a serious error that should be corrected.

Launer says that the book's prologue tells of the catastrophes inflicted by God on the hero. In fact, a more careful reading of the prologue will reveal that it was Satan, not God, who inflicted the catastrophes. God's role was permissive in that he removed the protective "hedge" that He had placed around Job and allowed Satan access to "everything he has."

Paul E Plsek, consultant Paul E Plsek and Associates, 1005 Allenbrook Lane, Roswell, GA 30075, USA paulplsek@ DirectedCreativity.com

Competing interests: None declared.

1 Launer J. The Book of Job. BMJ 2007;335:453. (1 September.)

2 Holy Bible. Job 1, 9-12. (New International version.)

\section{Enlightenment, finally}

I found the Book of Job a fascinating medical classic ${ }^{1}$ : the serial misfortunes, the (well meaning, but misplaced) counselling from friends, and the refusal of the Higher Power to accept fault.

It's good to know that there was an evidence base for MMC/MTAS.

James M Taylor, senior house officer Woodend Hospital, Aberdeen AB15 6XS jamestaylor@doctors.net.uk Competing interests: JMT survived MMC/MTAS; some of his friends did not.

1 Launer J. The Book of Job. BMJ 2007;335:453. (1 September.)

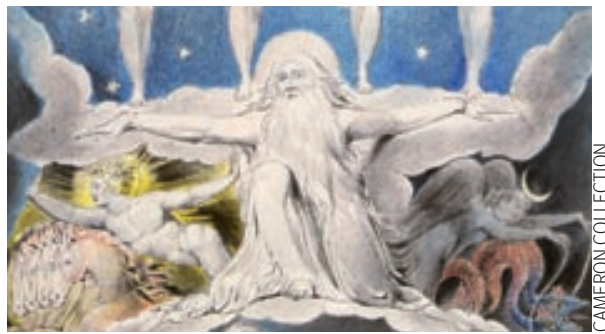

